\title{
Assessing Financial Integration in the European Union Equity Markets: Panel Unit Root and Multivariate Cointegration and Causality Evidence
}

\author{
Andrew C. Worthington \\ Griffith University \\ Helen Higgs \\ Griffith University
}

\begin{abstract}
This paper measures financial integration among selected European Union equity markets over the period July 1990 to June 2006 using daily data. Eleven markets (Austria, Belgium, Denmark, France, Germany, Greece, Ireland, Italy, Netherlands, Spain and the United Kingdom) are included in the analysis. Panel unit root tests are used to test for non-stationarity, and multivariate cointegration, Granger causality and level VAR procedures and variance decompositions are conducted to examine the equilibrium and causal relationships among these markets. The results indicate that there is a stationary long-run equilibrium relationship among and significant and substantial short and long run causal linkages between these markets. The findings offer complementary evidence that a high level of financial integration now prevails in the region.
\end{abstract}

- JEL Classification: C33, F36, G15

- Key Words: Financial Integration, International Capital Allocation, Economic Development and Growth, Market Efficiency

\footnotetext{
*Corresponding address: Andrew C. Worthington; Department of Accounting, Finance and Economics, Griffith University, 170 Kessels Road, Nathan QLD 4111, Australia, Tel: +61 73735 4273, Fax: +61 73735 3719, e-mail: a.worthington@griffith.edu.au./Helen Higgs; Department of Accounting, Finance and Economics, Griffith University, 170 Kessels Road, Nathan QLD 4111, Australia, Tel: +61 73735 7732, Fax: +61 73735 3719, e-mail: h.higgs@griffith.edu.au.

@ $2010-C e n t e r$ for International Economics, Sejong Institution, Sejong University, All Rights Reserved.
} 


\section{Introduction}

Financial integration is the process in which a country's or region's financial markets, including its money, bond, bank credit and equity markets, become more closely integrated with those in other countries or regions. More particularly, the market for a set of financial instruments and/or services is said to be fully integrated if all potential market participants with the same relevant characteristics: (i) face a single set of rules when they deal with these financial instruments and/or services; (ii) have equal access to the set of financial instruments and/or services; and (iii) are treated equally when they are active in the market (Baele et al. 2004).

In terms of outcomes, three benefits accrue from the process of financial integration: (i) more opportunities for risk sharing and diversification, (ii) the better allocation of capital across investment opportunities, and (iii) the potential for higher economic growth. First, sharing risk across regions enhances specialisation, increases the set of financial instruments and/or services available, and thereby provides additional possibilities for diversification by investors. Second, the elimination of barriers to trading, clearing and settlement allows firms to choose the most efficient location for their financing activities. Investors too are free to invest their funds to their most productive end-use. Finally, the improvement in capital allocation enhances financial development, thereby assisting the process of economic growth, with additional funds flowing to (often less-developed) countries or regions with more (and often better) productive opportunities.

The European Union (EU), currently celebrating the fiftieth anniversary of its establishment, is a potential exemplar of the process of financial integration. Starting with the six-member European Economic Community (EEC) in 1957, the EU is now the world's largest economic entity with a nominal GDP of $€ 11.5$ (US\$15.0) trillion spread across 27 member states, including the 13 members of the single-currency euro area. Obviously, financial integration has been an ongoing goal of the EU with an early emphasis placed on the elimination of cross-border restrictions on the activities of firms and investors within the region, as well as the harmonisation of rules, taxes and regulations among member states. More recently, however, the pace of these changes has accelerated, alongside a surge in crossborder trading. For instance, in the last few years the Financial Services Action Plan has been established as the vehicle for developing a single market in financial services in the EU, with more than forty measures to be implemented in the areas of banking, securities, insurance and pensions, and asset management (European 
Commission, 2007). At the same time, the European System of Central Banks (ESCB) and the European Central Bank (ECB) have since 1998 focused on financial integration as a means of achieving their primary objective of price stability alongside a high level of employment and sustainable and non-inflationary growth. This has resulted in series of regular updates on the pace and progress of financial integration by both the European Commission (2006) and the ECB (2007).

In a recent ECB occasional paper, Baele et al. (2004) identify several developments, particularly in equity markets, that suggest that financial integration has increased substantially in the EU. First, equity market participation by all types of investors has increased considerably, with equity as a share of financial assets held almost doubling between 1995 and 1999 (almost certainly associated with aging populations and the supplementation of public pensions with personal retirement savings). Second, the convergence of interest rates across euro area countries to historically low levels has prompted a reallocation of investments towards equity markets. Third, a number of EU directives have removed many of the few remaining barriers to international equity investment. Fourth, rapid growth in the number of investment funds has made it easier for investors to construct welldiversified portfolios.

Finally, with the introduction of the single currency in 1999, a structural shift occurred in the portfolio allocation paradigm, with investors increasingly convinced that the traditional first step of the international asset allocation decision in terms of country selection should give way to industry or sector selection, at least in the EU (Baele et al. 2004). In turn, the heightened interest in cross-border equity trading has led the region's stock exchanges to expand across national borders, with the consolidation of existing exchanges and attempts to create panEuropean exchanges: complicated in part by cross-country regulatory differences and the fragmentation in clearing and settlement systems (Baele et al. 2004).

Baele et al. (2004) use this evidence to argue for the monitoring and understanding of financial market integration. The reasons are as follows. First, while the benefits of financial integration are expected to be positive overall, less positive effects may arise where, say, excessive consolidation in a market segment hinders competition. Second, it is important to accurately measure the state of integration in various segments of the market so that areas where further initiatives are required are identified. Third, as monetary policy is implemented through the financial system, this system must be as efficient as possible in order to guarantee 
the smooth and effective transmission of monetary policy. Finally, financial integration affects the structure of the financial system, which in turn may have implications for financial stability. Monitoring integration is therefore important for regulators and central banks.

In Baele et al. (2004), the relative importance of sector and country effects, the proportion of local equity market variance explained by common factors, and changes in equity home bias are used separately to assess the degree of financial integration. However, a complementary approach exists in the form of multivariate cointegration, causality and variance decomposition methods to examine these sorts of pricing relationships. This builds upon a continuously evolving literature concerned with financial market integration, comprising studies addressing the integration of European member-states with global markets. See, for instance, Arshanapalli and Doukas (1993), Abbott and Chow (1993), Espitia and Santamaria (1994), Kwan et al. (1995), Richards (1995), Longin and Solnik (1995), Malliaris and Urrutia (1996), Solnik et al. (1996), Darbar and Deb (1997), Meric and Meric (1997), Shawky et al. (1997), Yuhn (1997), Francis and Leachman (1998), Ramchand and Susmel (1998), Masih and Masih (1999) and Cheung and Lai (1999). It also builds upon a relatively recent body of work focusing on the institutional and regulatory aspects and outcomes of integration within Europe, especially the role of European Monetary Union (EMU) and the single currency. See, for example, Cheung and Lai (1999), Rouwenhorst (1999), Frantzscher (2002), Worthington et al. (2003), Hartmann et al. (2003), Jian et al. (2003), Reszar (2005), Batten and Kearney (2006), Schotman and Zalewska (2006), Fonteyne (2006), Hardouvelis (2006), Kim et al. (2006) and Papadogonona and Stouraras (2006)].

Accordingly, the purpose of this paper is to present a quantitative method for assessing financial integration in EU equity markets. The paper itself is divided into four main areas. Section II presents the data employed in the analysis. Section III explains the methodology. Section IV discusses the results. The paper ends with some brief concluding remarks in Section V.

\section{Data}

The data employed in the study is composed of value-weighted equity market indices for 11 European markets, namely, Austria (AUS), Belgium (BEL), Denmark (DEN), France (FRA), Germany (GER), Greece (GRE), Ireland (IRL), 
Italy (ITL), Netherlands (NTH), Spain (SPN) and the United Kingdom (UK). While the sample of member states is not exhaustive, it does include the largest 11 of the 15 members in place before the 2004 and 2007 waves of accession (with 10 and 2 new members, respectively). All index data specified is obtained from Morgan Stanley Capital International-Barra (2007) (hereafter MSCI) in US dollar terms and encompasses the period 1 January 1993 to 31 June 2006. The construction of these indices is as follows:

In constructing a country index every listed security in the market is identified. Securities are free float adjusted, classified in accordance with the Global Industry Classification Standard $\left(\right.$ GICS $\left.^{\circledR}\right)$, and screened by size and liquidity. MSCI then constructs its indices by targeting for index inclusion $85 \%$ of the free float adjusted market capitalization in each industry group, within each country. By targeting $85 \%$ of each industry group, the MSCI Country Index captures $85 \%$ of the total country market capitalization while it accurately reflects the economic diversity of the market.

MSCI indices are widely employed in the financial integration literature given the degree of comparability, the avoidance of dual listing and the breadth and reflectivity of index coverage [see, for instance, Meric and Meric (1997), Yuhn (1997), Cheung and Lai (1999) and Worthington et al. (2003)]. The daily data used comprise the longest continuous time series for the eleven equity markets. Each market encompasses 4,175 daily observations; the eleven markets together provide a balanced panel of 45,925 observations.

\section{Empirical Methodology}

This paper investigates the integration among EU equity markets as follows. Panel unit root tests are first conducted as a means of informing subsequent techniques. Multivariate cointegration, Granger causality, level VAR and variance decomposition methods are then employed to examine the integration among markets.

\section{A. Panel Unit Root Tests}

Panel unit root tests comprise a multivariate analogue to standard univariate unit root tests, including the Augmented Dickey-Fuller (ADF), Phillips-Perron (PP) and Kwiatkowski, Phillips, Schmidt and Shin (KPSS) tests. The main purpose in extending the application of purely time-series unit root tests to panel unit root tests 
is to use the increase in sample size from pooling cross-sectional data to improve the power of the tests. Three panel unit root tests are examined, namely: the Levine, Lin and Chu (2002), Im, Pesaran and Shin (2003) and Hadri (2000) tests.

\section{1) A Basic Model}

Assume the time series $\left\{y_{i, 0}, \ldots, \mathrm{y}_{i, T}\right\}$ on the cross section units (or markets) $i=$ $1,2, \ldots, M$ over $T$ time periods are generated for each $i$ by a simple first-order autoregressive, $\mathrm{AR}(1)$, process:

$$
y_{i, t}=\left(1-\rho_{i}\right) \mu_{i}+\rho_{i} y_{i, t-1}+\varepsilon_{i, t} \quad i=1,2, \ldots, M, \quad t=1,2, \ldots, T
$$

where $y_{i, t}$ denotes the observed cross section for the $i$-th unit at time $t$ and $\varepsilon_{\mathrm{i}, \mathrm{t}}$ is white noise for the $i$-th unit at time $t$. The errors $\varepsilon_{i, t}$ are identically and independently distributed (i.i.d) across $i$ and $t$ with $E\left(\varepsilon_{i, t}\right)=0, E\left(\varepsilon_{i, t}^{2}\right)=\sigma_{i}^{2}<\infty$ and $E\left(\varepsilon_{i, t}^{4}\right)<\infty$. Under the null hypothesis of a unit root, $\rho_{i}=1$ for all $i$, equation (1) can be rewritten as the following basic ADF specification:

$$
\Delta y_{i, t}=\alpha_{i}+\phi_{i} y_{i, t-1}+\sum_{j=1}^{q_{i}} \gamma_{i, j} \Delta y_{i, t-j}+\varepsilon_{i, t}
$$

where $\alpha=\left(1-\rho_{i}\right) \mu_{i}, \phi_{i}=\left(\rho_{i}-1\right)$ and $y_{i}$ are coefficients to be estimated for the $i$-th unit, $q_{i}$ is the number of lagged terms for the $i$-th unit $\Delta y_{i, t}=y_{i, t}-y_{i, t-1}$ and all other parameters are as previously defined.

\section{2) Levine, Lin and Chu Test}

One of the first panel unit root tests was proposed by Levine and Lin (1992) and subsequently formalised in Levine et al. (2002) (hereafter LLC). The LLC test permits the intercept, time trend, residual variance and higher-order autocorrelations to vary across individual markets. The LLC test is based on a pooled panel estimator which assumes a common $\phi_{i}=\phi$ but allows $q_{i}$ to vary across the cross sections. It also requires the independently generated time series to have a common sample size. The LLC test may then be viewed as a pooled ADF test potentially with different lag lengths across the cross sections of the panel. The main limitation of this test is that it imposes a cross-equation restriction on the first-order autocorrelation coefficients. Under the LLC, the null and alternative hypotheses are given as: 


$$
\begin{gathered}
\mathrm{H}_{0, \mathrm{LLC}}: \phi_{1}=\phi_{2}=\ldots=\phi_{M}=0 \\
\mathrm{H}_{1, \mathrm{LLC}}: \phi_{1}=\phi_{2}=\ldots=\phi_{M}=\phi<0
\end{gathered}
$$

Under the null hypothesis, each cross section has a unit root (or is non-stationary) while under the alternative each cross section unit is stationary. The LLC test statistic under the null hypothesis is a modified $t$-statistic.

\section{3) Im, Pesaran and Shin Test}

The Im, Pesaran and Shin (2003) test (herafter IPS) is introduced to take account of the major weakness of the LLC test where it is assumed that all individual $\mathrm{AR}(1)$ series have a common autocorrelation coefficient. It allows for individual processes by permitting $\phi_{i}$ to vary across the cross sections. The IPS test begins by specifying a separate ADF regression for each cross section unit specified by equation (2). The null and alternative hypotheses for the IPS test are:

$$
\mathrm{H}_{0, \mathrm{IPS}}: \phi_{i}=\phi=0 \text { for } \forall i
$$

$\mathrm{H}_{1, \mathrm{IPS}}: \phi_{i}<0$ for $i=1,2, \ldots, M_{l}$ and $\phi_{i}=0$ for $i=M_{l}+1, \ldots, M$

Under the null hypothesis, all cross section units in the panel are non-stationary. The IPS test assumes that under the alternative at least one cross section unit, but not all cross section units is stationary. This differs from the LLC test which presumes all cross section units are stationary under the alternative hypothesis.

The IPS test is based on $M$ independent tests on $M$ cross section units while the LLC test combines the test statistics. The random errors, $\varepsilon_{i, t}$, are assumed to be serially correlated with different serial correlation properties and different variances across each cross section unit. The core of the IPS test is based on a group-mean $t$ bar statistic where the $t$-statistics are drawn from each ADF test and averaged across the panels. Adjustment factors are used to standardise the $t$-bar statistic into a standard normal IPS $W$-statistic under the null hypothesis.

\section{4) Hadri Test}

The Hadri (2000) panel unit root test parallels the well-known KPSS unit root test with the null hypothesis of no unit root in any of the cross section units in the panel. As with the KPSS unit root test, the Hadri test is based on the residuals from individual OLS regressions of $y_{i, t}$ on a constant or a constant and a trend. The test statistic is distributed as standard normal under the null. The error process may be assumed to be homoskedastic across the panel or heteroskedastic across the cross section units. Two $Z$-statistics are presented. One $Z$-statistic is derived from the 
Lagrange Multiplier (LM) statistic where the residuals from the ADF regression are associated with the homoskedasticity assumption across the panel and the other using the LM statistic that is heteroskedasticity consistent.

\section{B. Multivariate Cointegration}

Following Engle and Granger (1987), suppose the set of M market index series $y_{t}=\left[y_{1 t}, y_{2 t}, \ldots, y_{M t}\right]^{\prime}$ are all $\mathrm{I}(1)$ and $\beta y_{t}=u_{t}$ is $\mathrm{I}(0)$, then $\beta$ is said to be a cointegrated vector and $\beta^{\prime} y_{t}=u_{t}$ is called the cointegrating regression. The components of $y_{t}$ are said to be cointegrated of order $d$, denoted by $y_{t} \sim \mathrm{CI}(d, b)$ where $d>b>0$, if (i) each component of $y_{t}$ is integrated of order $d$, and (ii) there exists at least one vector $\beta=\left(\beta_{1}, \beta_{2}, \ldots, \beta_{\mathrm{M}}\right)$, such that the linear combination is integrated of $(d-b)$. By Granger's theorem, if the indices are cointegrated, they can be expressed in an error correction model (ECM) encompassing the notion of a long-run equilibrium relationship and the introduction of past disequilibrium as explanatory variables in the dynamic behaviour of current variables.

In order to implement the ECM, the order of cointegration must be known. A useful statistical test for determining the cointegration order proposed by Johansen (1991) and Johansen and Juselius (1990) is the trace test. For example, to test for no cointegrating relationship, $r$ is set to zero and the null hypothesis is $H_{0}: r=0$ and the alternative is $H_{1}: r>0$. However, the Johansen (1991) test can be affected by the lag order. The lag order is determined by using both the likelihood ratio test and information criteria in VAR. The optimum number of lags to be used in the VAR models is determined by the likelihood ratio test statistic:

$$
L R=(T-K) \ln \left(\left|\Sigma_{0}\right| /\left|\Sigma_{A}\right|\right)
$$

where $T$ is the number of observations, $K$ denotes the number of restrictions, $\Sigma$ denotes the determinant of the covariance matrix of the error term, and subscripts 0 and $A$ denote the restricted and unrestricted VAR, respectively. LR is asymptotically distributed $\chi^{2}$ with degrees of freedom equal to the number of restrictions. The test statistic in (3) is used to test the null hypothesis of the number of lags being equal to $k-1$ against the alternative hypotheses that $k=2,3, \ldots$ and so on. The test procedure continues until the null hypothesis fails to be rejected, thereby indicating the optimal lag corresponds to the lag of the null hypothesis. 


\section{Multivariate Granger Causality and Level VAR Tests}

To examine the short-run relationships among the markets, Granger (1969) causality tests are specified. Essentially tests of the prediction ability of time series models, a market index causes another index in the Granger sense if past values of the first index explain the second, but past values of the second index do not explain the first. When the indices in question are cointegrated, Granger causality is tested using the ECM:

$$
\Delta y_{t}=\gamma_{0}+\sum_{i=1}^{r} \psi_{i} \Theta_{t-1}+\sum_{i=1}^{m} \gamma_{i} \Delta y_{t-i}+\varepsilon_{t}
$$

where $\Theta$ contains $r$ individual error-correction terms, $r$ are long-term cointegrating vectors via the Johansen procedure, $\psi$ and $\gamma$ are parameters to be estimated, and all other variables are as previously defined.

One problem with a Granger causality test based on (4) is that it is affected by the specification of the model. ECM is estimated under the assumption of a certain number of lags and cointegrating equations, which means that the actual specification depends on the pre-test unit root and cointegration (Johansen) tests. To avoid possible pre-test bias, Toda and Yamamoto (1995) propose the level VAR procedure. Essentially, the level VAR procedure is based on VAR for the level of variables with the lag order $p$ in the VAR equations given by $p=k+d_{\max }$, where $k$ is the true lag length and $d_{\max }$ is the possible maximum integration order of variables. Therefore, the estimated VAR is expressed as:

$$
y_{t}=\hat{\gamma}_{0}+\hat{\gamma}_{1} t+\ldots+\hat{\gamma}_{q} q^{q}+\hat{J}_{1} y_{t-1}+\ldots \hat{J}_{k} y_{t-k}+\ldots+\hat{J}_{p} y_{t-p}+\hat{\varepsilon}_{t}
$$

where $t=1, \ldots, T$ is the trend term and $\hat{\gamma}_{i}, \hat{J}_{i}$ are parameters estimated by OLS. Note that $d_{\max }$ does not exceed the true lag length $k$. Equation (5) can be written as:

$$
Y=\hat{\Gamma} \Lambda+\hat{\Phi} X+\hat{\Psi} Z+\hat{E}^{\prime}
$$

where $\hat{\Gamma}=\left(\hat{\gamma}_{0}, \ldots, \hat{\gamma}_{q}\right), \quad \Lambda=\left(\tau_{1}, \ldots, \tau_{T}\right)$ with $\tau_{t}=\left(1, t, \ldots, t^{q}\right), \quad \hat{\Phi}=\left(\hat{J}_{1}, \ldots, \hat{J}_{k}\right)$, $\hat{\Psi}=\left(\hat{J}_{k+1}, \ldots, \hat{J}_{p}\right), X=\left(x_{1}, \ldots, x_{T}\right)$ with $x_{t}=\left(y_{t-1}^{\prime}, \ldots, y_{t-k}^{\prime}\right)^{\prime}, Z=\left(z_{1}, \ldots, z_{T}\right)$ with $z_{t}=\left(y_{t-k-1}^{\prime}, \ldots, y_{t-p}^{\prime}\right)^{\prime}$ and $\mathrm{E}=\left(\hat{\varepsilon}_{1}, \ldots, \hat{\varepsilon}_{T}\right)$. As restrictions in parameters, the null hypothesis $H_{0}: f(\phi)=0$ where $\phi=\operatorname{vec}(\Phi)$ is tested by a Wald statistic defined as: 


$$
W=f(\hat{\phi})^{\prime}\left[F(\hat{\phi})\left\{\hat{\Sigma}_{\varepsilon} \otimes(X Q X)^{-1}\right\} F(\hat{\phi})^{\prime}\right]^{-1} f(\hat{\phi})
$$

where $F(\phi)=\partial f(\phi) / \partial \phi^{\prime}, \hat{\Sigma}_{\varepsilon}=T^{-1} \hat{\mathrm{E}} \hat{\mathrm{E}}, Q=\hat{Q}_{\tau}-\hat{Q}_{\tau} Z\left(Z Q_{\tau} Z\right)^{-1} Z \hat{Q}_{\tau}$ and $\hat{\boldsymbol{Q}}_{\tau}=\boldsymbol{I}_{T}-\hat{\Lambda}\left(\hat{\Lambda}^{\Lambda^{\prime}} \hat{\Lambda}\right)^{-1} \hat{\Lambda}^{\prime}$ where $I_{T}$ is a $T \times T$ identity matrix. Under the null hypothesis, the Wald statistic (7) has an asymptotic Chi-square distribution with $m$ degrees of freedom that corresponds to the number of restrictions. Although Toda and Yamamoto (1995) present this method principally for the purpose of Granger-causality testing, tests based on level VAR equations can also be used to examine long-run relationships. Test results based on the ECM can then be regarded as an indicator of short-run causality, while the causality tests by the level VAR can complement the result of the cointegration tests in terms of long-run information.

\section{Variance Decomposition}

One limitation of these tests is that while they indicate which markets Grangercause another, they do not indicate whether yet other markets can influence a market through other equations in the system. Likewise, Granger causality does not provide an indication of the dynamic properties of the system, nor does it allow the relative strength of the Granger-causal chain to be evaluated. However, decomposition of the variance of forecast errors allows the relative importance of the variance in causing fluctuations in that market to be ascertained. The decomposition process therefore allows the variance of the forecast errors to be divided into percentages attributable to innovations in all other markets and a percentage attributable to innovations in the market of interest. One problem here is that the decomposition of variances is sensitive to the assumed origin of the shock and the order it is transmitted to other markets. To overcome this problem, a generalised impulse response analysis, which is not subject to any arbitrary othogonalisations of innovations in the system, is applied.

The variance decomposition analysis illustrates the system dynamics by decomposing the random variation of one market into component shocks and analysing how these shocks in turn affect prices in other markets. Consider the following VAR model of $m$ market indices proposed by Eun and Shim (1989: 243):

$$
y_{t}=\alpha+\sum_{S=1}^{n} A(S) y_{t s}+e_{t}
$$


where $y_{t}$ is a $m \times 1$ vector of indices, $\alpha$ and $A(S)$ are respectively $m \times 1$ and $m \times m$ coefficients, $n$ is the lag length, and $e_{t}$ is a $m \times 1$ column of forecast errors of the best linear predictor of $y_{t}$ using past values of $y$. By construction, if the forecast error $e_{t}$ is uncorrelated with all past values of $y$ and is also a linear combination of current and past $y_{t}$, then $e_{t}$ is serially uncorrelated. The $i, j$ component of $A(S)$ measures the direct effect of the $j$ th market on the $i$ th market in $S$ periods. As shown by Sim (1980), by the successive substitution of $e_{t} s$ into $y_{t-s}$, the VAR model becomes the following moving average representation where the price of each market is a function of past innovations of other markets:

$$
y_{t}=\sum_{S=0}^{\infty} B(S) e_{t s}
$$

Given $e_{t}$ is serially uncorrelated, the components of $e_{t}$ may be contemporaneously correlated. To observe the structure of the response of each market to a unit shock in another market within $S$ periods, the error term is transformed by the triangular orthogonalisation procedure. Let $e=V u$ where $V$ is a lower triangle matrix and $u$ is an orthogonalised innovation from $e$ such that $E e e^{\prime}=S$ and $V V^{\prime}=S$ and the transformed innovation $u_{t}$ has an identity covariance matrix. Equation (9) can then be re-written as:

$$
y_{t}=\sum_{S=0}^{\infty} B(S) V u_{t S}=\sum_{S=0}^{\infty} C(S) u_{t s}
$$

where $C(S)=B(S) V$. The i.jth component of $C(S)$ represents the impulse response of the $i$ th market in $S$ periods to a shock of one standard error in the $j$ th market. From the orthogonalised innovations, the forecast variance of each market can also be decomposed into portions accounted by shocks or innovations from other markets. The orthogonalisation generates the quantity $\sum_{S=0}^{T} C_{i j}^{2}(S)$, which is the proportion of forecast error variance of $y_{i}$ from innovations in $y_{j}$. This variance decomposition provides a measure of the overall relative importance of the markets in generating fluctuations in their own and other markets.

\section{Empirical Results}

Table 1 provides the panel unit root tests comprising statistics for the LLC $t$, IPS $W$ and Hadri homoskedastic and heteroskedastic $Z$-tests and corresponding $p$ values at price levels and first differences for the 11 markets. The LLC $t$ test 
statistic and $p$-value for the price level series are 1.2728 and 0.8985 , respectively. This indicates that the sample evidence on the entire panel of markets does not provide sufficient evidence to reject $\mathrm{H}_{0, \mathrm{LLC}}$. This suggests that there is insufficient evidence to conclude that each individual price level series is stationary. The LLC $t$-test for the first-differenced price series on the panel produced a $t$-statistic of 234.4400 and a $p$-value of 0.0000 , which concludes the rejection of $\mathrm{H}_{0, \mathrm{LLC}}$ at the five percent level of significance. The rejection of the null hypothesis indicates that each price differenced series is stationary.

With the IPS test at price levels across the 11 markets, the IPS $W$-statistic of 2.1629 and $p$-value of 0.9847 show that the null hypothesis, $\mathrm{H}_{0, \mathrm{IPS}}$, that all crosssection units in the panel are non-stationary cannot be rejected. The IPS panel unit root test indicates that at the price level all of these markets are non-stationary. The first-differenced series across all 11 European markets gives a IPS $W$-statistic of 196.1210 and a $p$-value of 0.0000 thus rejecting the null, $\mathrm{H}_{0, \mathrm{IPS}}$ which concludes that at least one of the price-differenced series in the 11 European markets is stationary. Turning to the Hadri homoskedastic and heteroskedastic $Z$ tests of the null hypothesis that all series in the panel are stationary; for the price level series, the null hypothesis is rejected with a homoskedastic $Z$ statistic of 68.0786 and a $p$ value of 0.0000 and a heteroskedastic $Z$ statistic of 53.8621 and a $p$-value of 0.0000 . This suggests that the price level series for all markets tend to be nonstationary. With respect to the first-differenced series, the Hadri homoskedastic $Z$ statistic of 0.2629 and $p$-value of 0.3963 and the heteroskedastic $Z$-tests of 0.3778 and $p$-value of 0.3528 fail to reject the required null, thus indicating that all price differenced series are stationary.

Table 1. Panel Unit Root Tests

\begin{tabular}{crrrr}
\hline & \multicolumn{2}{c}{ Levels Series } & \multicolumn{2}{c}{ First-Differenced Series } \\
\cline { 2 - 5 } & \multicolumn{1}{c}{ Statistic } & \multicolumn{1}{c}{$p$-value } & \multicolumn{1}{c}{ Statistic } & $p$-value \\
\hline Levin, Lin \& Chu $t^{*}$ & 1.2728 & 0.8985 & -234.4400 & 0.0000 \\
Im, Pesaran and Shin $W$-statistic & 2.1629 & 0.9847 & -196.1210 & 0.0000 \\
Hadri Homoskedastic $Z$-statistic & 68.0786 & 0.0000 & 0.2629 & 0.3963 \\
Hari Heteroskedastic $Z$-statistic & 53.8621 & 0.0000 & 0.3778 & 0.3528 \\
\hline
\end{tabular}

Notes: Period 2/7/1990-30/6/2006; hypotheses $\mathrm{H}_{1, \mathrm{LLC}}$ : each series is stationary, $\mathrm{H}_{1, \mathrm{IPS}}$ : at least one series is stationary, $\mathrm{H}_{1}$ (Hadri homoskedastic and heteroskedastic Z-stat) each series is non-stationary; the lag orders are determined by the significance of the coefficient for the lagged terms; for the price levels series intercepts and trends are included; for the first differenced price series only intercepts are included. 
According to the panel unit root tests, analysis of the price level series indicates non-stationarity while the first-differenced price forms exhibit stationarity for all 11 European markets. The finding of non-stationarity in levels and stationarity in differences suggests that each index price series is integrated of order I(1). The finding of non-stationarity in levels and stationarity in differences provides comparable evidence to other studies of European equity markets using lesspowerful univariate unit root tests. In terms of subsequent modelling procedure, the differenced series are then used to carry out lag length selection, causality tests and decomposition of the forecast error variance for the markets to be analysed.

Johansen cointegration tests are used in order to obtain the cointegration rank. The eigenvalues and trace test statistics are detailed in Table 2 for the various null and alternative hypotheses. As the multivariate cointegration tests cover all eleven markets rather than the simple bivariate combinations found in much of the earlier work, they consider the full scope of financial integration relationships that may be found. The trace test statistic is greater than the critical value for the null hypotheses of $r=0$ thereby rejecting the null hypothesis. However, the null hypothesis of $r \leq 1$ fails to be rejected in favour $r>1$ indicating the order of cointegration is 1 . However, similar hypothesis are rejected up to, but not including, $r \leq 4$ thereby suggesting an order of integration of four. The primary finding obtained from the Johansen cointegration tests is that a stationary long-run relationship exists between the markets. Thus, there is a tendency for the markets

Table 2. Johansen Cointegration Tests

\begin{tabular}{cccrc}
\hline $\mathrm{H}_{0}$ & $\mathrm{H}_{1}$ & Eigen-Value & Trace Test & Critical Value \\
\hline $\mathrm{r}=0$ & $\mathrm{r}>0$ & 0.0346 & $* * 507.7293$ & 310.8100 \\
$\mathrm{r} \leq 1$ & $\mathrm{r}>1$ & 0.0216 & $* * 360.9169$ & 263.4200 \\
$\mathrm{r} \leq 2$ & $\mathrm{r}>2$ & 0.0194 & $* * 269.7053$ & 222.2100 \\
$\mathrm{r} \leq 3$ & $\mathrm{r}>3$ & 0.0134 & $* * 187.8190$ & 182.8200 \\
$\mathrm{r} \leq 4$ & $\mathrm{r}>4$ & 0.0085 & 131.4605 & 146.7600 \\
$\mathrm{r} \leq 5$ & $\mathrm{r}>5$ & 0.0079 & 95.7882 & 114.9000 \\
$\mathrm{r} \leq 6$ & $\mathrm{r}>6$ & 0.0046 & 62.8146 & 87.3100 \\
$\mathrm{r} \leq 7$ & $\mathrm{r}>7$ & 0.0037 & 43.4112 & 62.9900 \\
$\mathrm{r} \leq 8$ & $\mathrm{r}>9$ & 0.0034 & 27.8572 & 42.4400 \\
\hline
\end{tabular}

Accepted

Notes: Period 2/7/1990-30/6/2006; 0.05 percent level critical values from Osterwald-Lenum (1992); the optimal lag order of each VAR model selected using LR tests for the significance of the coefficient for maximum lags and Schwarz's Bayesian Information Criterion; in each cointegrating equation, the intercept and trend are included. 
in the long run not to drift too far apart (or move together).

As cointegration exists, Granger causality tests are performed based on equation (4). $F$-statistics are calculated to test the null hypothesis that the first index series does not Granger-cause the second, against the alternative hypothesis that the first index Granger-causes the second. The calculated statistics and $p$-values for the markets are found in Table 3. Among the eleven European markets 50 significant causal links are found (at the 0.10 level or lower). For example, as shown Greece, Ireland, Spain and the UK markets affect the Austrian market (column 1) and Spain (column 10) is found to have a Granger causal relationship with Austria, Belgium, France, Germany and Ireland.

Further insights are gained by examining the rows in Table 3 indicating the effects of a particular market on all markets. In the short run, it is evident that the most influential markets are Austria, Belgium, Germany, Ireland, Spain and the UK. Germany, for example, influences seven European markets, including France, Greece, Ireland, Italy, Netherlands, Spain and the UK. The least influential markets in terms of Granger-causality are the Netherlands, which has no influence across any other European markets, and Italy, which only affects Ireland. There is also an indication that there is feedback at play in several pairwise combinations. For example, the UK market Granger-causes the Irish market and Ireland Grangercauses the UK market. This suggests a common pricing factor and close integration. Using the total number of causal and caused relationships as one indicator of integration, Austria, Ireland, Spain, Germany, the UK and Belgium are relatively more integrated, while Denmark, France, Greece, Italy and the Netherlands are less integrated.

While it is not easy to explain these results on a one-to-one correspondence with market features (not least because the equity indexes are not from a single exchange), it does appear that the more integrated markets are those with more active and larger markets. For example, the London Stock Exchange (UK) and BME Spanish Exchanges (Spain) are Europe's largest by investment flow (IPOS and secondary market issues), while they and the Deutsche Börse are largest by value of share trading and turnover velocity. Likewise, Baele et al. (2004) identifies Germany, Spain and Belgium as countries with an above-average contribution of euro-area factors influencing local returns. However, while it is relatively easy to see why small markets like Denmark, Greece, and the Netherlands are less integrated, it is difficult to explain why Austria and Ireland appear more integrated and why large markets France and Italy are poorly integrated. One possibility is 
Table 3. Granger (Short-run) Causality Tests

\begin{tabular}{cccccccccccccc}
\hline Market & AUS & BEL & DEN & FRA & GER & GRE & IRL & ITL & NTH & SPN & UNK & Causes \\
\hline AUS & - & 2.8775 & 0.0403 & 6.9258 & 6.46 W87 & 3.4153 & 16.2037 & 3.2945 & 3.6133 & 4.6302 & 6.5114 & 9 \\
& & $\mathbf{0 . 0 8 9 9}$ & 0.8410 & $\mathbf{0 . 0 0 8 5}$ & $\mathbf{0 . 0 1 1 0}$ & $\mathbf{0 . 0 6 4 7}$ & $\mathbf{0 . 0 0 0 1}$ & $\mathbf{0 . 0 6 9 6}$ & $\mathbf{0 . 0 5 7 4}$ & $\mathbf{0 . 0 3 1 5}$ & $\mathbf{0 . 0 1 0 8}$ & \\
BEL & 0.0011 & - & 0.6480 & 6.4561 & 3.6017 & 0.0979 & 1.3436 & 4.6061 & 14.1388 & 2.7154 & 12.0870 & 6 \\
& 0.9735 & & 0.4209 & $\mathbf{0 . 0 1 1 1}$ & $\mathbf{0 . 0 5 7 8}$ & 0.7544 & 0.2465 & $\mathbf{0 . 0 3 1 9}$ & $\mathbf{0 . 0 0 0 2}$ & $\mathbf{0 . 0 9 9 5}$ & $\mathbf{0 . 0 0 0 5}$ & \\
DEN & 0.5668 & 4.0443 & - & 1.5453 & 0.0546 & 0.0947 & 2.1862 & 1.5336 & 3.9339 & 0.6663 & 1.3032 & 2 \\
& 0.4516 & $\mathbf{0 . 0 4 4 4}$ & & 0.2139 & 0.8152 & 0.7584 & 0.1393 & 0.2156 & $\mathbf{0 . 0 4 7 4}$ & 0.4144 & 0.2537 & \\
FRA & 0.2535 & 1.6394 & 0.0318 & - & 0.4223 & 0.0365 & 0.9811 & 0.7732 & 0.3647 & 10.1735 & 2.0033 & 1 \\
& 0.6147 & 0.2005 & 0.8584 & & 0.5158 & 0.8485 & 0.3220 & 0.3793 & 0.5459 & $\mathbf{0 . 0 0 1 4}$ & 0.1570 & \\
GER & 0.1508 & 0.8510 & 2.1828 & 27.6069 & - & 5.4352 & 23.8636 & 2.7274 & 8.0321 & 13.4407 & 3.6336 & 7 \\
& 0.6978 & 0.3563 & 0.1396 & $\mathbf{0 . 0 0 0 0}$ & & $\mathbf{0 . 0 1 9 8}$ & $\mathbf{0 . 0 0 0 0}$ & $\mathbf{0 . 0 9 8 7}$ & $\mathbf{0 . 0 0 4 6}$ & $\mathbf{0 . 0 0 0 2}$ & $\mathbf{0 . 0 5 6 7}$ & \\
GRE & 9.5215 & 0.5931 & 4.3850 & 1.9003 & 0.8514 & - & 3.3586 & 3.0319 & 1.8592 & 2.3358 & 1.4820 & 4 \\
& $\mathbf{0 . 0 0 2 0}$ & 0.4413 & $\mathbf{0 . 0 3 6 3}$ & 0.1681 & 0.3562 & & $\mathbf{0 . 0 6 6 9}$ & $\mathbf{0 . 0 8 1 7}$ & 0.1728 & 0.1265 & 0.2235 & \\
IRL & 8.8577 & 24.0211 & 0.9978 & 36.2855 & 25.2748 & 0.2197 & - & 15.1257 & 35.7305 & 11.6243 & 15.0112 & 8 \\
& $\mathbf{0 . 0 0 2 9}$ & $\mathbf{0 . 0 0 0 0}$ & 0.3179 & $\mathbf{0 . 0 0 0 0}$ & $\mathbf{0 . 0 0 0 0}$ & 0.6393 & & $\mathbf{0 . 0 0 0 1}$ & $\mathbf{0 . 0 0 0 0}$ & $\mathbf{0 . 0 0 0 7}$ & $\mathbf{0 . 0 0 0 1}$ & \\
ITL & 0.0677 & 0.4723 & 0.0139 & 0.0000 & 2.1370 & 0.5665 & 2.9701 & - & 0.0186 & 0.0260 & 0.2927 & 1 \\
& 0.7948 & 0.4920 & 0.9062 & 1.0000 & 0.1439 & 0.4517 & $\mathbf{0 . 0 8 4 9}$ & & 0.8916 & 0.8718 & 0.5885 & \\
NTH & 1.8930 & 0.8316 & 0.0090 & 0.6268 & 0.0000 & 0.2124 & 2.5590 & 1.0949 & - & 0.3596 & 1.9657 & 0 \\
& 0.1689 & 0.3619 & 0.9243 & 0.4286 & 1.0000 & 0.6449 & 0.1097 & 0.2954 & & 0.5488 & 0.1610 & \\
SPN & 5.5212 & 12.5830 & 0.7121 & 0.8630 & 15.9029 & 1.6156 & 10.1582 & 3.1065 & 5.3337 & - & 8.4140 & 7 \\
& $\mathbf{0 . 0 1 8 8}$ & $\mathbf{0 . 0 0 0 4}$ & 0.3988 & 0.3530 & $\mathbf{0 . 0 0 0 1}$ & 0.2038 & $\mathbf{0 . 0 0 1 4}$ & $\mathbf{0 . 0 7 8 1}$ & $\mathbf{0 . 0 2 1 0}$ & & $\mathbf{0 . 0 0 3 7}$ &
\end{tabular}

Notes: Granger causality tests conducted by adjusting the long-term cointegrating relationship by the ECM; The figures in the second row for each market are $p$-values; tests indicate Granger causality by row to column and Granger caused by column to row. For example, in the period 2/7/1990-30/6/2006 Denmark (row) Granger causes two markets (Belgium and Netherlands) and is Granger-caused by Greece and the United Kingdom. Significant values $(p \leq 0.10)$ are in bold. 
Table 4. Long-run Causality Tests by Level-VAR

\begin{tabular}{|c|c|c|c|c|c|c|c|c|c|c|c|c|}
\hline Market & AUS & BEL & DEN & FRA & GER & GRE & IRL & ITL & NTH & SPN & UNK & Causes \\
\hline \multirow[t]{2}{*}{ AUS } & - & 19.1517 & 51.2433 & 11.8869 & 9.1537 & 12.5420 & 19.8368 & 4.4451 & 7.3285 & 14.7364 & 14.5401 & 7 \\
\hline & & 0.0018 & 0.0000 & 0.0364 & 0.1031 & 0.0281 & 0.0013 & 0.4873 & 0.1973 & 0.0116 & 0.0125 & \\
\hline \multirow[t]{2}{*}{ BEL } & 9.3728 & - & 15.8705 & 21.8089 & 26.5413 & 1.1245 & 17.6701 & 16.7832 & 24.3238 & 18.2103 & 31.2184 & 9 \\
\hline & 0.0951 & & 0.0072 & 0.0006 & 0.0001 & 0.9519 & 0.0034 & 0.0049 & 0.0002 & 0.0027 & 0.0000 & \\
\hline \multirow[t]{2}{*}{ DEN } & 4.1465 & 5.2530 & - & 3.5774 & 2.6979 & 45.9024 & 4.2056 & 3.0735 & 4.1642 & 8.3081 & 6.2007 & 1 \\
\hline & 0.5285 & 0.3858 & & 0.6117 & 0.7464 & 0.0000 & 0.5202 & 0.6887 & 0.5260 & 0.1401 & 0.2872 & \\
\hline \multirow[t]{2}{*}{ FRA } & 3.6743 & 10.4406 & 20.6097 & - & 5.1518 & 7.6468 & 9.5436 & 2.4328 & 4.2439 & 14.3631 & 10.1284 & 5 \\
\hline & 0.5972 & 0.0637 & 0.0010 & & 0.3976 & 0.1768 & 0.0892 & 0.7866 & 0.5149 & 0.0135 & 0.0717 & \\
\hline \multirow[t]{2}{*}{ GER } & 7.3379 & 4.9341 & 12.8234 & 33.3345 & - & 8.3184 & 29.1488 & 4.4652 & 14.2813 & 21.8116 & 9.5473 & 6 \\
\hline & 0.1967 & 0.4240 & 0.0251 & 0.0000 & & 0.1395 & 0.0000 & 0.4846 & 0.0139 & 0.0006 & 0.0891 & \\
\hline \multirow[t]{2}{*}{ GRE } & 15.4974 & 5.7350 & 20.2962 & 6.5946 & 2.3835 & - & 16.2591 & 8.7250 & 6.6917 & 6.8899 & 11.3059 & 4 \\
\hline & 0.0084 & 0.3329 & 0.0011 & 0.2526 & 0.7939 & & 0.0061 & 0.1205 & 0.2446 & 0.2290 & 0.0456 & \\
\hline \multirow[t]{2}{*}{ IRL } & 7.1180 & 23.5513 & 1.4377 & 28.8990 & 22.2911 & 1.3599 & - & 11.4911 & 27.2761 & 7.6627 & 11.9725 & 6 \\
\hline & 0.2120 & 0.0003 & 0.9201 & 0.0000 & 0.0005 & 0.9286 & & 0.0425 & 0.0001 & 0.1758 & 0.0352 & \\
\hline \multirow[t]{2}{*}{ ITL } & 2.7212 & 6.5619 & 3.9878 & 3.6668 & 3.9126 & 2.2692 & 4.3567 & - & 1.7325 & 6.1276 & 2.3038 & 0 \\
\hline & 0.7429 & 0.2553 & 0.5512 & 0.5983 & 0.5621 & 0.8108 & 0.4993 & & 0.8848 & 0.2940 & 0.8057 & \\
\hline \multirow[t]{2}{*}{ NTH } & 8.6514 & 2.8433 & 6.5932 & 15.2500 & 8.1486 & 5.0710 & 7.1534 & 18.0115 & - & 14.8676 & 16.6881 & 4 \\
\hline & 0.1238 & 0.7241 & 0.2527 & 0.0093 & 0.1482 & 0.4073 & 0.2095 & 0.0029 & & 0.0109 & 0.0051 & \\
\hline \multirow[t]{2}{*}{ SPN } & 8.6394 & 21.6071 & 17.9425 & 4.2997 & 20.6386 & 7.8976 & 18.5474 & 6.0106 & 10.6800 & - & 10.7128 & 6 \\
\hline & 0.1243 & 0.0006 & 0.0030 & 0.5071 & 0.0009 & 0.1620 & 0.0023 & 0.3052 & 0.0581 & & 0.0574 & \\
\hline \multirow[t]{2}{*}{ UNK } & 11.7893 & 5.2362 & 5.4203 & 7.6200 & 10.6451 & 8.8088 & 26.1819 & 8.2876 & 19.2408 & 17.2831 & - & 5 \\
\hline & 0.0378 & 0.3877 & 0.3668 & 0.1785 & 0.0589 & 0.1169 & 0.0001 & 0.1411 & 0.0017 & 0.0040 & & \\
\hline Caused & 3 & 4 & 6 & 5 & 4 & 2 & 7 & 3 & 5 & 6 & 8 & 53 \\
\hline
\end{tabular}

Notes: Unbracketed figures in table are Wald statistics for Granger causality tests. The figures in the second row for each market are $p$-values. The level VAR are estimated with a lag order of $p=k+d_{\max } ; \mathrm{k}$ is selected by the LR test and $d_{\max }$ is set to one. Tests indicate Granger causality by row to column and Granger caused by column to row, for example, Greece (row) Granger causes four markets (Austria, Denmark, Ireland and the United Kingdom) and is Granger-caused by Austria and Denmark. Significant values $(p \leq 0.10)$ are in bold. 
that unmeasured institutional and behavioural restrictions on investor and capital flows explain better the lack of integration than market-based measures of activity and liquidity explains the presence of integration.

The long-run causality Wald test statistics and $p$-values based on Toda and Yamamoto's (1995) level VAR procedure are presented in Table 4. The model is estimated for the levels, such that a significant Wald test statistic indicates a longterm relationship. This serves to supplement the findings obtained from the Granger causality (short run) results in Table 3. Among the eleven markets, 53 significant causal links are found (at the 10 percent level or lower). For example, column 7 shows that the markets in Austria, Belgium, France Germany, Greece, Spain and the UK affect the Irish market; and the German market (column 5) is influenced by Belgium, Ireland, Spain and the UK. The rows in Table 4 indicate the effects of a particular market on all markets. The least influential market is Italy, which does not have any long-run influence on any other European markets.

However, these results should be interpreted with the qualification that short and long-run causality tests only indicate the most significant direct causal relationship. For example, it may be that some markets influence non-Granger caused markets indirectly through other markets. In order to address this concern, Table 5 presents the decomposition of the forecast error variance for the 2-day, 5-day, 10-day and 15-day-ahead horizons for the 11 markets. Each row indicates the percentage of forecast error variance explained by the market indicated in the first column. For example, at the 2-day horizon, the variance in the Austrian market explains $99.56 \%$ of its own innovations, whereas $0.13 \%$ of the variance is explained by innovations in the German market and $0.12 \%$ by the Spanish market. Five home markets, namely Austria, Denmark, Germany, Greece and Ireland explain at least 70\% of their own innovations, while with the remaining markets domestic influences on innovation range from $21.57 \%$ (France) to $47.10 \%$ (Belgium). The UK market significantly influences the German market by $19 \%$, even after 15 days.

It is readily apparent from the decomposition of the forecast error variance in Table 5 that sizeable differences in the percentage of variance explained by domestic and international markets prevail across the EU. In terms of their average influence on forecast error variance across other European markets at the 15-day horizon, Austria and Germany account for $16.4 \%$ and $19.3 \%$, respectively, while Italy and Denmark account for a mere $0.1 \%$ and $0.2 \%$ respectively. From a different perspective, Austria accounts for $98.7 \%$ of its own variance and Greece $87.0 \%$, down to the Netherlands at just $19.0 \%$ and France with $22.1 \%$. 
Table 5. Generalised Variance Decomposition(coundient)

\begin{tabular}{|c|c|c|c|c|c|c|c|c|c|c|c|c|c|}
\hline & Period & S.E. & AUS & BEL & $\overline{D E N}$ & FRA & GER & GRE & IRL & ITL & NTH & SPN & UNK \\
\hline \multirow[t]{4}{*}{ AUS } & 2 & 20.0880 & 99.5595 & 0.0013 & 0.0095 & 0.0086 & 0.1321 & 0.0647 & 0.0000 & 0.0001 & 0.0302 & 0.1189 & 0.0753 \\
\hline & 5 & 33.8036 & 99.1699 & 0.1004 & 0.0705 & 0.0418 & 0.1177 & 0.0361 & 0.0058 & 0.0257 & 0.1581 & 0.2289 & 0.0450 \\
\hline & 10 & 48.8391 & 98.9775 & 0.1086 & 0.0696 & 0.0874 & 0.1262 & 0.0195 & 0.0130 & 0.0566 & 0.3248 & 0.1468 & 0.0700 \\
\hline & 15 & 60.0813 & 98.7583 & 0.0936 & 0.0487 & 0.0975 & 0.1042 & 0.0315 & 0.0340 & 0.0857 & 0.5043 & 0.1112 & 0.1311 \\
\hline \multirow[t]{4}{*}{ BEL } & 2 & 17.8366 & 22.6932 & 47.1023 & 0.0520 & 0.0118 & 15.5033 & 0.0000 & 10.1451 & 0.0024 & 0.0013 & 4.4882 & 0.0005 \\
\hline & 5 & 28.6220 & 24.6366 & 48.0857 & 0.0856 & 0.0484 & 14.5748 & 0.0144 & 7.3308 & 0.1184 & 0.0034 & 5.0777 & 0.0242 \\
\hline & 10 & 39.7426 & 26.6880 & 48.3222 & 0.0613 & 0.0728 & 13.5932 & 0.0623 & 6.3547 & 0.1536 & 0.0075 & 4.5823 & 0.1022 \\
\hline & 15 & 48.1194 & 27.6343 & 47.8301 & 0.0435 & 0.0608 & 13.1505 & 0.1362 & 6.3927 & 0.1682 & 0.0207 & 4.3927 & 0.1705 \\
\hline \multirow[t]{4}{*}{ DEN } & 2 & 40.2585 & 12.1294 & 0.5716 & 71.2303 & 0.0202 & 5.1899 & 4.8856 & 4.5161 & 0.0001 & 0.0008 & 1.2579 & 0.1980 \\
\hline & 5 & 56.8819 & 17.8701 & 1.1107 & 63.0992 & 0.0801 & 6.9170 & 3.3240 & 4.8091 & 0.0152 & 0.0167 & 2.4424 & 0.3155 \\
\hline & 10 & 75.9165 & 22.9633 & 1.2556 & 56.8990 & 0.2998 & 7.5913 & 2.3912 & 4.7980 & 0.0258 & 0.0097 & 3.1725 & 0.5937 \\
\hline & 15 & 90.1619 & 26.1291 & 1.1900 & 52.5848 & 0.5367 & 7.9126 & 1.8711 & 4.9298 & 0.0543 & 0.0074 & 3.9276 & 0.8567 \\
\hline \multirow[t]{4}{*}{ FRA } & 2 & 18.3578 & 17.1558 & 1.0313 & 0.0551 & 21.5741 & 40.1790 & 0.0220 & 9.9158 & 0.0001 & 0.0213 & 7.5860 & 2.4596 \\
\hline & 5 & 28.2541 & 17.8527 & 2.4086 & 0.0308 & 21.9749 & 39.4470 & 0.0167 & 8.2694 & 0.0090 & 0.2134 & 7.5285 & 2.2490 \\
\hline & 10 & 38.9098 & 18.8260 & 2.7828 & 0.0689 & 22.3181 & 38.0890 & 0.0151 & 7.8762 & 0.0057 & 0.3078 & 7.0223 & 2.6883 \\
\hline & 15 & 46.9661 & 19.1034 & 2.8448 & 0.1342 & 22.1148 & 37.4418 & 0.0300 & 7.9836 & 0.0073 & 0.4156 & 6.9029 & 3.0217 \\
\hline \multirow[t]{4}{*}{ GER } & 2 & 20.6271 & 18.7082 & 0.0657 & 0.0001 & 0.0374 & 70.7748 & 0.0166 & 9.7285 & 0.0265 & 0.0006 & 0.5777 & 0.0639 \\
\hline & 5 & 32.1831 & 19.8205 & 0.9961 & 0.0558 & 0.1434 & 68.6853 & 0.0079 & 9.1643 & 0.0130 & 0.0373 & 1.0296 & 0.0467 \\
\hline & 10 & 44.7604 & 20.8904 & 1.4774 & 0.0454 & 0.2270 & 67.1756 & 0.0086 & 8.9750 & 0.0070 & 0.0271 & 0.9400 & 0.2265 \\
\hline & 15 & 54.0921 & 21.3597 & 1.5789 & 0.0330 & 0.2339 & 66.2547 & 0.0178 & 9.0987 & 0.0068 & 0.0359 & 0.9026 & 0.4780 \\
\hline \multirow[t]{4}{*}{ GRE } & 2 & 23.9226 & 1.6385 & 0.1598 & 0.0241 & 0.0119 & 0.6134 & 96.2677 & 1.1479 & 0.0017 & 0.0054 & 0.1061 & 0.0236 \\
\hline & 5 & 31.9924 & 2.3513 & 0.2970 & 0.2883 & 0.0580 & 1.6563 & 92.7448 & 1.7768 & 0.0127 & 0.0842 & 0.6964 & 0.0344 \\
\hline & 10 & 40.1188 & 3.0438 & 0.4112 & 0.4697 & & 2.6580 & 89.6822 & 2.1667 & 0.0103 & 0.2011 & 1.0818 & 0.1119 \\
\hline & 15 & 46.1146 & 3.6664 & 0.4555 & 0.8033 & 0.2301 & 3.3239 & 87.0521 & 2.4544 & 0.0125 & 0.3609 & 1.3399 & 0.3012 \\
\hline
\end{tabular}


Table 5. Generalised Variance Decomposition(continued)

\begin{tabular}{cccccccccccccc}
\hline IRL & 2 & 4.7052 & 17.5366 & 0.0040 & 0.0403 & 0.0261 & 0.9498 & 0.0014 & 81.1328 & 0.0286 & 0.0350 & 0.1162 & 0.1293 \\
& 5 & 7.5075 & 18.3049 & 0.3197 & 0.1051 & 0.0238 & 1.8261 & 0.1225 & 78.2344 & 0.0423 & 0.1470 & 0.8141 & 0.0602 \\
& 10 & 10.4249 & 19.6873 & 0.6205 & 0.0831 & 0.0163 & 2.2423 & 0.3131 & 75.7245 & 0.0373 & 0.1552 & 0.9957 & 0.1249 \\
& 15 & 12.5869 & 20.3320 & 0.8066 & 0.0583 & 0.0373 & 2.4816 & 0.5256 & 74.1615 & 0.0370 & 0.1818 & 1.1207 & 0.2577 \\
ITL & 2 & 6.1646 & 15.9276 & 0.6078 & 0.0123 & 1.4475 & 25.1087 & 0.0357 & 7.9107 & 37.9288 & 0.0268 & 10.2631 & 0.7309 \\
& 5 & 9.7293 & 15.8916 & 1.3078 & 0.0130 & 1.6567 & 24.7790 & 0.0427 & 7.1566 & 37.6156 & 0.2536 & 10.6891 & 0.5943 \\
& 10 & 13.5418 & 16.4880 & 1.4931 & 0.0103 & 1.8405 & 25.0521 & 0.0481 & 6.9669 & 36.3984 & 0.3153 & 10.5212 & 0.8660 \\
& 15 & 16.3317 & 16.8517 & 1.5499 & 0.0190 & 1.8346 & 25.1134 & 0.0500 & 7.0777 & 35.2788 & 0.4001 & 10.7053 & 1.1195 \\
NTH & 2 & 26.5391 & 14.6505 & 3.7521 & 0.0281 & 1.1547 & 34.0869 & 0.0027 & 12.3273 & 0.1144 & 24.3618 & 5.9722 & 3.5493 \\
& 5 & 40.2887 & 16.1814 & 6.0187 & 0.0136 & 1.4508 & 33.4070 & 0.0476 & 11.2141 & 0.0857 & 21.8296 & 6.1476 & 3.6038 \\
& 10 & 55.3666 & 17.6121 & 6.6149 & 0.0138 & 1.6419 & 32.4464 & 0.1006 & 11.1563 & 0.0549 & 20.2956 & 5.3361 & 4.7275 \\
& 15 & 66.7739 & 18.1575 & 6.5459 & 0.0246 & 1.6670 & 31.9479 & 0.1427 & 11.7292 & 0.0385 & 19.0041 & 4.9152 & 5.8274 \\
SPN & 2 & 5.4916 & 17.9114 & 0.0047 & 0.0069 & 0.0904 & 27.2180 & 0.0280 & 8.7079 & 0.0005 & 0.0204 & 45.9985 & 0.0134 \\
& 5 & 8.6063 & 19.5398 & 0.4250 & 0.0359 & 0.0455 & 25.2443 & 0.0270 & 7.6967 & 0.0125 & 0.1913 & 46.7060 & 0.0762 \\
& 10 & 11.8549 & 21.4212 & 0.6990 & 0.0346 & 0.0304 & 24.4943 & 0.0152 & 7.4407 & 0.0071 & 0.3483 & 45.4355 & 0.0736 \\
& 15 & 14.2628 & 22.1228 & 0.7566 & 0.1217 & 0.0213 & 23.8746 & 0.0106 & 7.7528 & 0.0049 & 0.5688 & 44.5564 & 0.2095 \\
UNK & 2 & 13.2889 & 14.2175 & 0.8546 & 0.0045 & 0.0236 & 20.1771 & 0.0155 & 13.8305 & 0.0075 & 0.0304 & 4.4911 & 46.3478 \\
& 5 & 20.0731 & 15.8828 & 2.2430 & 0.0409 & 0.0465 & 19.7345 & 0.0476 & 13.3501 & 0.0394 & 0.2284 & 5.8464 & 42.5404 \\
& 10 & 27.3949 & 17.3660 & 2.6960 & 0.1415 & 0.0608 & 19.3454 & 0.0400 & 13.0956 & 0.0891 & 0.1845 & 6.0137 & 40.9676 \\
& 15 & 32.9124 & 17.8485 & 2.8848 & 0.2557 & 0.0458 & 18.9133 & 0.0287 & 13.6135 & 0.1441 & 0.1789 & 6.1025 & 39.9842 \\
\hline
\end{tabular}

Notes: The ordering for the variance decomposition is based on the number of 'causes' in Table 3; the four rows for each market are in order of forecast periods of 2, 5, 10 and 15 days, respectively. 


\section{Concluding Remarks}

Financial integration is a long-standing policy goal in the EU, potentially benefiting its many member-states and their citizens through more opportunities for risk sharing and diversification, the better allocation of capital across investment opportunities, and the potential for higher economic growth. The results of this study are just one indication of a more integrated European equity market, in both the euro area and beyond, signalling that national stock market returns in the EU are increasingly driven by common (regional) news. This would provide prima facie evidence that institutional and regulatory change in the EU implemented through a variety of policy mechanisms, along with the changing behaviour of investors and financiers at the market level, has been successful in promoting the desired objective.

Of course, this analysis does suffer a number of limitations, all of which provide possible directions for future research on European financial integration. First, while the equity market is clearly an important dimension of the financial system, it is just one part alongside the money, bond and banking markets. Ample evidence suggests that the degree of integration varies depending on the market segment, with financial integration usually more advanced in market segments other than equity. For example, as the money market lies closer to the single monetary policy in the euro area, it will be relatively more integrated. It would then be interesting to use similar techniques to those used in this paper to compare the level of integration in different market segments in the EU.

Second, while there is ample allowance in this study for local and regional factors in pricing equity in Europe, there is no recognition of global factors arising principally from the US, Japan or even China. This makes it difficult to gauge the relative impact of global, regional and local factors in European equity markets, and thereby make a more complete assessment of financial integration. This is equivalent to assuming that the influence of non-EU markets is constant across those markets included. However, focusing on a smaller set of closely related markets allows better insights and a more tractable analysis than what might otherwise be the case. Finally, this study provides a broad assessment of financial integration for the entire period and across all markets. It therefore is unable to comment on the relative pace of integration over this period, the role of the various institutional and regulatory changes in this process, especially the introduction of the single currency, and the differential impacts on the member-states. By splitting the sample period into, say, a 
period before and after a major structural or institutional change, it may be possible to illustrate the impact of this change on financial integration. These limitations, of course, all provide useful directions for future research in this important area.

\section{Acknowledgements}

The authors would like to thank the editor (Hwan Ho Lee), an anonymous referee, and participants at the $15^{\text {th }}$ Global Finance Conference in Hangzhou and the $15^{\text {th }}$ International Economic Association Meeting in Istanbul for helpful comments on an earlier version of this paper. The authors also gratefully acknowledge the financial assistance of an Accounting and Finance Association of Australia and New Zealand (AFAANZ) Research Fund Grant and a Griffith Business School Small Research Grant.

Received 4 February 2010, Revised 8 April 2010, Accepted 20 April 2010

\section{References}

Abbot, A.B. and K.V. Chow. (1993), "Cointegration among European Equity Markets", Journal of Multinational Financial Management, 2(3-4), pp. 167-184.

Akdogan, H. (1995), The Integration of International Capital Markets: Theory and Empirical Evidence, Edward Elgar, Aldershot.

Arshanapalli, B. and J. Doukas. (1993), "International Stock Market Linkages: Evidence from the Pre- and Post- October 1987 Period", Journal of Banking and Finance, 17(1), pp. 193-208.

Baele, L., A. Ferrando, P. Hördahl, E. Krylova and C. Monnet. (2004), "Measuring Financial Integration in the Euro Area", Occasional Paper Series No. 14, European Central Bank. Available at: http://www.ecb.int/. Accessed April 2007.

Batten, J.A and C. Kearney. (2006), "Interdependence and Integration in Emerging European Financial Markets", in Emerging European Financial Markets: Independence and Integration Post-Enlargement, (Ed.) Batten, J.A. and C. Kearney. International Finance Review Series, Vol. 6. Elsevier, Amsterdam, pp. 1-14.

Cheung, Y.W. and K.S. Lai. (1999), "Macroeconomic Determinants of Long-term Stock Market Comovements among Major EMS Countries", Applied Financial Economics, 9(1), pp. 73-85.

Choi, I. (2001), "Unit Root Tests for Panel Data", Journal of International Money and Finance, 20(2), pp. 249-272.

Darbar, S.M. and P. Deb. (1997), "Co-movement in International Equity Markets", Journal of Financial Research, 20(3), pp. 305-322. 
Engle, R. F. and C.W.J. Granger. (1987), "Co-integration and Error Correction: Representation, Estimation, and Testing”, Econometrica, 55(2), pp. 251-76.

Espitia. M. and R. Santamaría. (1994), "International Diversification among the Capital Markets of the EEC", Applied Financial Economics, 4(1), pp. 1-10.

European Central Bank (2007), Financial Integration in Europe, March 2007. Available at: http://www.ecb.int/. Accessed April 2007.

European Commission (2006), Financial Integration Monitor 2006. Available at: http:// ec.europa.eu/. Accessed April 2007.

European Commission (2007), Financial Services Action Plan. Available at: http:// ec.europa.eu/. Accessed April 2007.

Fonteyne, W. (2006), "EU: From Monetary to Financial Union: Overcoming the Remaining Hurdles to Financial Integration in Europe", Finance and Development, 43(2), pp. 48-50.

Francis, B.B. and L.L. Leachman. (1998), "Superexogeneity and the Dynamic Linkages among International Equity Markets", Journal of International Money and Finance, 17(4), pp. 475-492.

Fratzscher, M. (2002), "Financial Market Integration in Europe: On the Effects of EMU on Stock Markets”, International Journal of Finance and Economics, 7(3), pp. 165-193.

Granger, C.W.J. (1969), "Investigating Causal Relations by Econometric Models and Cross-spectral Methods", Econometrica, 37(3), pp. 424-438.

Hadri, K. (2000), “Testing for Stationarity in Heterogeneous Panel Data", Econometrics Journal, 3(2), pp. 148-161.

Hardouvelis, G.A., D. Malliaropulos and R. Priestley. (2006), "EMU and European Stock Market Integration", Journal of Business, 79(1), pp. 365-92.

Hartmann P., A. Maddaloni and S. Manganelli. (2003), "The Euro Area Financial System: Structure, Integration and Policy Initiatives", Oxford Review of Economic Policy, 19(1), pp. 180-213.

Im, K.S., M.H. Pesaran and Y. Shin. (2003), "Testing for Unit Root in Heterogeneous Panels", Journal of Econometrics, 115(1), pp. 53-74.

Jian, Y., M. Insik and L. Qi. (2003), "European Stock Market Integration: Does EMU Matter?", Journal of Business Finance and Accounting, 30(9-10), pp. 1253-1276.

Johansen, S. (1991), "Estimation and Hypothesis Testing of Cointegration Vectors in Gaussian Vector Autoregressive Models, Econometrica, 59(6), pp. 1551-1580.

Johansen, S. and K. Juselius. (1990), "Maximum Likelihood Estimation and Inferences on Cointegration - With Applications to the Demand for Money", Oxford Bulletin of Economics and Statistics, 52(2), pp. 169-210.

Kim, S.J., F. Moshirian and E. Wu. (2006), "Evolution of International Stock and Bond Market Integration: Influence of the European Monetary Union”, Journal of Banking and Finance, 30(5), pp. 1507-34.

Koo, J. and S. Lee. (2000) "Regional Income Convergence: Evidence from Panel Unit Root Tests", Seoul Journal of Economics, 13(4), pp. 459-469.

Kwan, A.C.C. A.B. Sim and J.A. Cotsomitis. (1995), "The Causal Relationships between 
Equity Indices on World Exchanges", Applied Economics, 27(1), pp. 33-27.

Levin, A., C.-F. Lin and C.-S.J. Chu. (2002), "Unit Root Tests in Panel Data: Asymmetric and Finite-sample Properties", Journal of Econometrics, 108(1), pp. 1-24.

Malliaris, A.G. and J.L. Urrutia. (1996), "European Stock Market Fluctuations: Short and Long Term Links", Journal of International Financial Markets, Institutions and Money, 6(2-3), pp. 21-33.

Meric, I. and G. Meric. (1997), "Co-movements of European Equity Markets Before and After the 1987 Crash", Multinational Finance Journal, 1(2), pp. 137-152.

Morgan Stanley Capital International Barra (2007), http://www.mscibarra.com/ accessed January 2007.

Osterwald-Lenum, M. (1992), "Note with Quantiles of the Asymptotic Distribution of the Maximum Likelihood Cointegration Rank Test Statistics", Oxford Bulletin of Economics and Statistics, 54, pp. 461-72.

Papadogonas, T. and Y. Stournaras. (2006), "Financial Integration, National Savings and National Investment in the EU Member-states", Applied Economics Letters, 13(14), pp. 953-56.

Ramchand, L. and R. Susmel. (1998), "Volatility and Cross-correlation across Major Stock Markets", Journal of Empirical Finance, 5(4), pp. 397-416.

Reszat, B. (2005), "How has the European Monetary Integration Process Contributed to Regional Financial Market Integration?", A New Financial Market Structure for East Asia (Ed.) Park, Y.C., I. Takatoshi, and W. Yunjong, Elgar, Cheltenham, pp. 104-38.

Richards, A.J. (1995), "Comovements in National Stock Market Returns: Evidence of Predictability, but not Cointegration”, Journal of Monetary Economics, 36(3), pp. 631-654.

Rouwenhorst, K.G. (1999), "European Equity Markets and EMU: Are the Differences between Countries slowly Disappearing?” Financial Analysts Journal, May-June, pp. 57-64.

Schotman, P.C, and A. Zalewska. (2006), "Non-synchronous Trading and Testing for Market Integration in Central European Emerging Markets", Journal of Empirical Finance, 13(4-5), pp. 462-94.

Shawky, H.A. R. Kuenzel, and A.D. Mikhail. (1997), "International Portfolio Diversification: A Synthesis and an Update", Journal of International Financial Markets, 7(4), pp. 303-327.

Toda, H.Y. and T. Yamamoto. (1995), "Statistical Inference in Vector Autoregressions with Possibly Integrated Processes", Journal of Econometrics, 66(1-2), pp. 225-250. Worthington, A.C., M. Katsuura and H. Higgs. (2003), "Financial Integration in European Equity Markets: The Final Stage of Economic and Monetary Union (EMU) and its Impact on Capital Markets", Economia, 54(1), pp. 79-99.

Yuhn, K.H. (1997), "Financial Integration and Market Efficiency: Some International Evidence from Cointegration Tests", International Economic Journal, 11(2), pp. 103-116. 